\title{
TOP-DOWN OR BOTTOM-UP? EMPLOYING A MIDDLE-GROUND APPROACH IN DESIGNING A UK ACADEMIC WRITING COURSE FOR ADVANCED CHINESE GRADUATES
}

\author{
Ivo Ganchev \\ ${ }^{1}$ Queen Mary University of London and Peking University, UK, China \\ E-mail: i.ganchev@qmul.ac.uk/ivoganchev@pku.edu.cn
}

\begin{abstract}
This article documents the academic writing course design process for advanced Chinese learners aiming to pursue postgraduate degrees in business-related fields at their respective target universities in the UK. Four holders of BA degrees in the social sciences from second tier universities in Beijing were tested, surveyed and observed in detail to design a non-terminal twenty-hour pre-sessional writing course (ten two-hour sessions) to assist in their preparation for postgraduate study. All students held offers from Russell Group universities in the UK and had covered the IELTS requirement (6.5-7.0) for admission there prior to signing up for the EAP course discussed in this paper. The aim of the course is to enhance the students' academic skills and improve their performance in the following year when they attend UK universities. The course design process is informed by two sets of principles, incorporating both a top-down and a bottom-up perspective. The former is framed within an understanding of EAP as academic, rather than language training. The latter is based on needs analysis of student-specific weaknesses explored through the use of a questionnaire, a diagnostic writing test and in-class observations. Both perspectives feed into the course goals and objectives which serve as a basis for the course rationale. Aiming to bridge the gap between Chinese undergraduate and UK postgraduate study, the course combines textbooks with authentic materials and formative with summative assessment. Reflections on major constraints and limitations are provided throughout the process. This documented case of academic writing course design aims to reveal challenges faced by EAP practitioners working with UK and Chinese institutions, and to present a middle ground approach to resolving tensions between top-down and bottom-up pressures in the context of course design for advanced Chinese graduates.
\end{abstract}

Key words: EAP, UK, China, course development, needs analysis, writing

\section{INTRODUCTION}

English for Academic Purposes (EAP) is often defined as "the linguistic, sociolinguistic and psycholinguistic description of English as it occurs in the contexts of academic study and scholarly exchange itself' (Hamp-Lyons, 2005: 89). This embodies the dual nature of EAP as: a) a gateway to tertiary study and academia at English-language institutions; and b) a subdomain of English for Specific Purposes (ESP). The former is shaped by long-standing academic traditions sustained by a top-down hierarchy where academics implicitly impose

Submitted January $2^{\text {nd }}, 2020$, accepted for publication February $28^{\text {th }}, 2020$

(C) 2020 by University of Niš, Serbia | Creative Commons License: CC BY-NC-ND 
writing structure, expressions and terminology on younger scholars through the dissemination of their publications and through practices that form part of their teaching. Learning to follow these practices has high stakes for incoming students on English-language programmes and for aspiring academics in non-English speaking countries, creating a stable trend towards the global expansion of EAP. Academic courses welcome students from a variety of backgrounds and thus, must be designed in response to their specific needs. This creates a tension between academic standards which are imposed top-down and student needs which are identified bottom-up, posing challenges to course design.

In the first part of this article, I present salient characteristics of EAP in contrast with General English, using a top-down approach to derive course design principles as a general framework based on established academic practices and requirements in a UK context. Then, I analyse the specific needs of students who are preparing to pursue graduate degrees in the UK, adopting a bottom-up approach to inform course design. Combining top-down and bottom-up approaches, I present a case of resolving tension between the two by documenting the course design process for a group of four advanced Chinese graduates preparing to study in the UK. Given the steady yearly increase of Chinese students coming to the UK, this case presents a record of practical challenges faced frequently by EAP practitioners in the UK and China, and of potential solutions.

\subsection{Discourse community}

Academia is a classic example of a discourse community. Swales (1990: 21-32) identifies six characteristics of this concept as "common public goals," "mechanisms of intercommunication among its members," "participatory mechanisms [for] feedback," specific genres, specific lexis and a "threshold level of... expertise [of its members]". All six are embodied in university marking criteria, and in the peer review process of academic journals. Some note that the use of English as an academic lingua franca, e.g. in science, carries political implications and places some students at a disadvantage (Tardy, 2004: 264-5). In practice, EAP courses are the closest that academia comes to mitigating this; they aim to ensure students are able to engage within their subject-specific discourse communities and efficiently participate in academic debates, especially at the graduate level. This enables students to: a) perform to the best of their abilities on their degree programme and receive appropriate recognition for that through their grades; b) impactfully present potentially innovative research findings, contributing to existing literature in their fields. Well-prepared incoming EAP students often rightly mention both as course expectations. EAP tutors may not have the subject-specific expertise to initiate students into their respective discourse communities (Spack, 1988); hence, strong course design needs to include elements of: a) linguistic and technical ability to engage in academic debates; b) psycholinguistic understanding of collective knowledge building.

\subsection{Materials}

There are three common views on textbook use in academic literature on EAP: a) strong anti-textbook; b) weak anti-textbook; and c) pro-textbook (Harwood, 2005: 154). While this typology is a broadly accurate reflection of popular views among many scholars, it omits a fourth possibility, namely a weak pro-textbook stance. As Swales (1995: 6) rightly points out, it is tutors who "orchestrate the use of textbooks in classes." Textbook-style teach-test activities are only intended as a foundation for developing academic skills which different groups require 
to varying extents. Academic debates indicate that while it does not offer a strong advantage in any one particular aspect, this often neglected middle-ground position presents an optimal solution for balancing between the expectations of institutions, tutors and learners. It provides universities with a foundation for an accreditable curriculum design, tutors with a bank of ideas, and students with a written guide to their course. Meanwhile, selectively incorporating level-appropriate "authentic" materials (full-length, unedited and in their original format) can supplement a coursebook-based curriculum.

Adopting corpus-based learning activities addresses potential criticisms of subjectivity in material selection and presents a practical resource to the tutor. McEnery et al. (2006: 4) define a corpus as "a collection of (1) machine-readable (2) authentic texts [...] (3) sampled to be (4) representative of a particular language or language variety". Older EAP coursebooks are based on unsubstantiated, subjective perceptions of content relevance (Lockett, 1999: 50); for instance, Coxhead's (2000) Academic Word List inspired textbooks such as Schmitt and Schmitt (2005). This was followed by the rise of corpora which revealed great diversity in academic English; prominent examples include the British Corpus of Written Academic English (BAWE; Nesi, 2008), the English as an Academic Lingua Franca Project (ELFA; Mauranen, 2006) and the Michigan Corpus of Academic Spoken English (MICASE) which study different registers varying from UK written to international to US spoken English. Enabling students to use corpora empowers students, alleviating frequent language accuracy errors and stimulating self-study by enabling the verification of collocations, prepositions and set phrases.

\subsection{Autonomy}

Assuming responsibility for one's own learning is crucial for university study and a key element of progressive EAP. Lynch's (2013) research at the University of Edinburgh suggests a very strong correlation between self-perceived progress on EAP courses and the amount of self-study hours students spend on their preparation; he argues for encouraging students to engage more actively in conversations and discussions. Inside the classroom, peer evaluation (Lynch, 1988) and group-project-based learning (Grant, 2017) offer incentives for engagement. Employing traditional e-learning platforms, e.g. Blackboard and Moodle, as well as newer mobile applications, e.g. Schoology (Ardi, 2017) can also offer access to additional resources and file sharing support while decreasing the traditional teacher-student and strong-weak student power imbalance; online learning rarely presents technical difficulties to students. Finally, the complexity of factors influencing feedback makes it "multidirectional" (Unlu and Wharton, 2015: 35) as writing norms, tutor input and student needs influence the process. Recent research demonstrates students are more likely to engage with and respond efficiently to feedback which is learner-driven (still provided by a tutor but 'directed' by the student; Maas, 2017).

\subsection{Implications for course design}

This section has identified four main challenges for designing an EAP course curriculum; each of them stems from top-down pressures which are rooted in the nature of academia as a discourse community. Alongside each challenge, a potential conceptual solution was presented to inform my course design proposal outlined later in this article. First, I will adopt a weak pro-textbook approach to balance the interests of institutions, tutors and students, not rejecting the benefits of textbooks but selectively exploiting and supplementing them. Next, I 
will encourage the students' psycholinguistic understanding of discourse communities, partly by developing their language skills at the text level to understand essay structure and its relationship to text purpose. Third, I will encourage learner autonomy through stimulating greater use of English outside of the classroom, online and through project-based assignments which require continuous, critical engagement with authentic sources. Providing tutor feedback and holding in-class discussions on draft elements of the project will enable students to engage critically with literature and use expert sources appropriately in their own writing to avoid possible plagiarism. Finally, corpus-based classroom activities and self-exploring will have a supplementary role in my course design.

\section{NEEDS ANALYSIS}

Having previously taught the students my course will be designed for (see Table 1 for group profile), I had informal conversations with them and their past tutors at a language centre affiliated with Beijing Union University. My group contains four advanced students holding BA degrees in the social sciences from different second tier universities in Beijing. I was asked to design a pre-sessional course focused on academic writing; the course would be non-compulsory for the students and includes twenty contact hours split into ten sessions of two hours each. Prior to taking the course, my students had obtained admission offers from their respective target UK universities (all of which are Russell Group members) and had covered their respective IELTS requirements (6.5-7.0). In the process of executing needs analysis (NA), the students were tested, surveyed and observed in detail; the methodology and data summary are presented below.

The students demonstrated strong academic potential in their respective fields. They self-identified their aim as improving academic skills in order to perform as well as possible on UK degree programmes in the following year. My group exhibits both intrinsic ('[which] comes within the individual') and extrinsic ('caused by any number of outside factors') motivation (Harmer, 2001: 51). While student performance will be quantified in the next academic year and acts as an extrinsic factor, their strong track records and determination suggests that they obtain enjoyment from learning. The fact that the surveyed students signed up to take my non-compulsory course prior to their departure to the UK was an act of making visible effort in their studies.

Table 1 Learner Group Profile

\begin{tabular}{|l|l|l|l|}
\hline Previous Education & \multicolumn{3}{|l|}{ BA graduates, second-tier universities in Beijing } \\
\hline Number of Students & 4 & Age Range & $22-24$ \\
\hline Male / Female Ratio & $2: 2$ & Country of Origin & China \\
\hline First Language & Mandarin & Years of English Study & $15-17$ (2-3 hrs/wk) \\
\hline Target Institutions & \multicolumn{4}{|l|}{ Russell Group UK universities (all students are offer holders) } \\
\hline Target Degrees & Masters-level degrees in business-related fields \\
\hline Start Date & Sep. '18 & IELTS Scores & 6.5-7.0 (obtained) \\
\hline
\end{tabular}

\subsection{Genre focus: argumentative essay}

Prior to conducting NA, it was important to identify the types of texts that students will be required to produce on business studies graduate courses in the UK and correlate that 
with my students' previous experience in order to gear the NA process toward focusing on the writing genre(s) that students need most assistance with. Business studies tutors in the UK set two types of assignments; the first one is reports. Occasionally, modules with a strong element of social science input such as marketing and organisational behaviour include assessment in the form of individual or group reports on case studies. However, reports are already a widely popular genre in the Chinese university system; moreover, they are factual accounts and content structure does not differ significantly across cultures. Hence, this course will not focus on reports.

The second type of texts business students are often required to produce in the UK are argumentative essays. The understanding of this genre differs vastly across Chinese and British culture and these differences have been explored extensively by the EAP community. For instance, Xu (2015) rightly notes that indirectness in Chinese rhetoric makes it difficult for students to understand the concept of placing a topic sentence at the beginning of a paragraph. Mattison (2007) rightly notes China has a 'high context' culture and the author's intended meaning is often expected to be assumed by the reader; moreover, Chinese students frequently adopt a wholistic view of a problem and think in terms of 'both-and', rather than the 'either-or' framework characteristic of Western academia. These and other cultural differences, such as the relatively frequent use of literary devices in Chinese academic writing, translate poorly into a Western academic context. UK universities expect students to write non-ambiguously and state their arguments directly. Hence, the focus of this course will be building up the students' skillset to prepare them for writing an argumentative essay.

\subsection{Methodology: needs analysis and diagnostic test}

Needs analysis (NA) is both subjective and objective (West, 1994: 4). It includes elements such as purpose of study, personal motivation and past experiences. Gardner and Winslow (1983:76) rightly view NA as necessary for the production of "information which when acted upon makes courses better adapted to students' needs." The course discussed in this article is non-terminal and builds on previous knowledge of English to prepare students for university degrees. It is taught in Beijing prior to the departure of the students for the UK where they will be completing masters-level degrees in business-related fields at Russell Group universities.

To complement the EAP principles imposed through top-down academic practices (identified in Section 1), I choose to rely on NA as a foundation for 'developing tests, materials, teaching activities, and evaluation strategies' for my EAP course (Brown 1995: 35). To minimize error probability, I triangulated (Denzin, 1978) information on learner preferences and styles as identified by: a) students through a questionnaire (Appendix 3, Part 1); b) myself through impressions of students in class (Appendix 3, Part 5). The questionnaire is purposefully designed to be broad as its primary aim is not to inform content, but types of activities. My students have previously struggled to pinpoint their specific weaknesses in writing. Hence, I relied on a diagnostic writing test (Appendix 3, Part 2), assessed through the increasingly popular MASUS (Measuring the Academic Skills of University Students; Bonanno and Jones, 2007) criteria (Appendix 3, Part 4). This produced quantitative data of weakness analysis and decreased the element of subjectivity in NA to improve test validity. My in-class observations to date (Appendix 3, Part 5) combined with my knowledge of target situation for the learners (Hutchinson and Waters, 1987: 55-6) informed my findings to a lesser but still relatively significant extent. 


\subsection{Findings}

Some recent EAP publications argue against the neurolinguistic argument for the validity of visual, auditory and kinaesthetic (VAK) analysis implied in my questionnaire in Appendix 3, Part 1 (Lethaby and Harries, 2015). However, such positions do not dispute that: a) students' prior knowledge is important to the achievement of learning outcomes and VAK preferences are likely influenced by prior knowledge; b) VAK questionnaires (Fleming and Mils, 1992) are a time-efficient method of gaining information about a group of learners. Thus, to inform my choice of activities, I employed a VAK questionnaire (Appendix 3, Part 1) to discover that my students seem to be mostly visual and kinaesthetic learners. All of them enjoy collaborative activities and 'strongly agree' that 'understanding an idea helps [them] learn better'.

My students prioritize improving their writing. The two main forms of argumentative writing on graduate UK programmes in business studies are exam papers and written coursework; both require students to defend a stance through building arguments. To focus on improving specific aspects of such tasks, I administered a diagnostic test (DT) to reveal the individual strengths and weaknesses of each student (Hughes, 2003: 50).

Designing appropriately linguistic input for my course required the accurate identification of student strengths and weaknesses; thus, it was important to ensure that the writing produced by students during the DT was original and authentic. Some of my students had previously memorised a number of business-related phrases in English and their repeated use concealed the ways of expression that they would use when conveying original thoughts. To avoid reliance on memorized expressions, the writing topic was not business-specific - instead, students were asked to write a 250-word argumentative paragraph defending a stance of their choice on changes in Chinese marriage practices, a topic they had previously shown interest in.

When writing argumentative essays at UK universities, students have access to a wide variety of sources and to electronic dictionaries/translators. However, allowing the use of either could severely distort the authenticity of the students' language in the DT essay. Besides, Chinese students tend to have frequent problems with plagiarism (James et al., 2019) and the capability of detection service such as Turnitin to identify it remains somewhat limited (Bensal et al., 2013), Hence, I ensured that students would not use electronic devices so as to avoid them copying text produced by native speakers or using automated translations of their own ideas (originally conceived in Chinese). The DT took place in a controlled environment allowing only limited access to excerpts from authentic materials as a substitute for an online search for academic source texts and the use of paper dictionaries as opposed to digital software.

This mirrored the conditions in which UK university students solve exam papers and simulated closely conditions under which they produce other writing assignments. My students were allowed ample time (up to three hours) for one short paragraph since they would normally have several days or weeks to complete lengthy coursework. The simulated environment would have arguably been more realistic if source text excepts were provided in digital format alongside electronic dictionaries and typing was completed on a computer but this was logistically impossible without allowing access to the internet at the DT location; therefore, writing was handwritten and completed in class.

The DT environment produced a highly accurate reflection of student strengths and weaknesses in exam conditions at a UK university. It mildly differed from the usually freer environment allowed when producing long argumentative essays and this could have possibly led to minor distortions in the collected data. These include, for instance concealing the 
potential inability of students to identify relevant sources or over-emphasizing the need for ensuring spelling accuracy as minor errors could have been amended with a spell-checker. While potentially present, such issues do not undermine the overall validity of the collected data as a reflection of the students' writing skills.

DT results demonstrated that students' main issues fall in ten areas as shown in Table 2 (below). This data was confirmed by incorporating concept checking questions in a follow-up teaching session to verify whether students indeed struggle with these language areas; some of the questions I used include:

- Is a reference included in the text or after the text? (Referencing)

- What is another way to say [X; or] that sentence? (Efficient Paraphrasing)

- Is there a way to indicate that $[\mathrm{X}]$ happens only $30 \%$ of the time? (Hedging)

Table 2 Weakest Academic Skills Demonstrated in the DT Results

\begin{tabular}{|l|c|}
\hline Academic Skill & Student Percentage* \\
\hline - referencing & $100 \%$ \\
- efficient paraphrasing & $100 \%$ \\
- critical evaluation of evidence & $100 \%$ \\
- appropriate choice of lexis & $75 \%$ \\
- appropriate choice of register & $75 \%$ \\
- academic style (as opposed to IELTS) & $75 \%$ \\
- appropriate use of data / arguments & $75 \%$ \\
- paragraph structure & $50 \%$ \\
* clear topic sentence & $50 \%$ \\
\hline
\end{tabular}

\subsection{Priorities}

Through involving students in course design, I engaged them to assume greater responsibility for their learning (Tudor, 1996). Based on informal conversations, perceived learner needs, target situation analysis and DT results, I identified the following priorities:

- achieving greater autonomy in research under guided supervision;

- developing greater self-awareness in the writing process;

- appropriately engaging with and referring to others' academic work;

- improving lexis accuracy and choosing more appropriate sentence structure.

NA revealed that students are at an upper-intermediate-to-advanced level. Prioritising their needs in my course design will allow them to proceed to a terminal EAP course where they will receive further training in writing longer research papers.

\section{COURSE PROPOSAL}

Students of ESP have 'external' aims to complete non-linguistic goals in the 'real world' (Basturkmen, 2010: 8). This means my students will need to complete academic work on their degree programmes after taking EAP courses. Graves (2000: 75-6) rightly contrasts between goals ('main purposes and intended outcomes') and objectives (which 'describe how the goals will be achieved'); the former are more general than the latter. 


\subsection{Goals and objectives}

The overall aim of my course is to prepare students for writing an argumentative essay at the graduate level. Course design will follow Nunan's (1988: 27) product-oriented approach seeking to equip students with relevant skills to improve their performance in the target situation. Goals and objectives (as summarised in Table 3 below) identified in this section are based on this target outcome and shaped by learning priorities determined in Section 2.4. Goals (coded G1 - G3) frame the overall purpose of the designed 20-hour course, while objectives $(\mathrm{O} 1-\mathrm{O} 8)$ formulate input and practice.

Table 3 Goals (coded G) and objectives (coded O)

\begin{tabular}{|c|l|}
\hline Code & By the end of the course, students will have: \\
\hline G1 & - become more autonomous learners; \\
G2 & - demonstrated (in writing) engagement in an academic debate (Business Studies); \\
G3 & - conveyed ideas in a structured and accurate manner (in an argumentative essay); \\
O1 & - mastered Harvard Referencing Style and understood the purpose of referencing; \\
O2 & - produced argumentative paragraphs where each sentence has a relevant purpose; \\
O3 & - reflected on their own work and on that of others according to given criteria; \\
O4 & - selected a topic of their choice and conducted some form of research on it; \\
O5 & - used appropriate structure to complete one full short academic essay; \\
O6 & - used new subject-specific lexis in their work; \\
O7 & - used less redundant phrases (no substantial meaning) than in the DT; \\
O8 & - tested preliminary versions of their arguments against colleagues and constructed \\
& improved versions in their final writing assignment. \\
\hline
\end{tabular}

\subsection{Course design: outline}

In line with Thornbury's (2013) recommendations and recent quantitative research (Kashef et al., 2014), I will adopt a student-centred approach to increase engagement, provoke critical thinking and foster self-assessment habits. As all students have already covered entry language requirements for their target universities and are relatively advanced learners, the course will aim at fostering comprehensive (rather than purely linguistic) skills. Stoller (1999) identifies three general areas for EAP skills: language (e.g. reading, writing,

Table 4 Rationale for syllabus structure

\begin{tabular}{|c|c|c|}
\hline EAP Area & $\begin{array}{c}\text { Goals / } \\
\text { Objectives }\end{array}$ & Rationale \\
\hline Technical & $\mathrm{O} 1, \mathrm{O} 3, \mathrm{O} 7$ & $\begin{array}{l}\text { - to ensure presentation is clear and avoid losing marks for } \\
\text { technical inaccuracies of failures to comply with formal } \\
\text { criteria; }\end{array}$ \\
\hline Language & $\mathrm{G} 3: \mathrm{O} 2, \mathrm{O} 6$ & - to increase efficiency of expression; \\
\hline Academic & G1: 04,08 & $\begin{array}{l}\text { - to develop independence in understanding given criteria } \\
\text { and in completing academic assignments; }\end{array}$ \\
\hline Acculturation & G2: O5 & $\begin{array}{l}\text { - to gain conceptual understanding about the purpose of } \\
\text { academia as collective knowledge-building body. }\end{array}$ \\
\hline
\end{tabular}


vocabulary), academic skills (e.g. critical thinking, research, note taking) and acculturation (e.g. understanding academic culture and expectations). These three aspects will form parts of the syllabus, along with a fourth, technical one (e.g. genre, structure, referencing). The rationale for focusing on these four areas of EAP is presented in Table 4 below.

\subsection{Approaches, activities and sequencing}

Goals and objectives should be central to the organising principles of a course (Graves, 2000: 125-7). I strive to foster skills for autonomous work to meet the goals set in 3.1. As already discussed above in 2.2, the final aim of my students will be to produce an argumentative essay; given their lack of previous experience in producing pieces of over 1,000 words and the relatively small number of sessions on the course, the length of their final essay will be limited to 1,500 words. Over the course, tasks will spiral from a paragraph to an essay.

Students will be allowed creative freedom in choosing their research topic and formulating a research question to develop autonomy and critical thinking (Alexander et al., 2008) - but they will receive peer feedback and tutor guidance on both in the process. Semi-structured seminar-style discussions in class will encourage self-reflection on the purposes of this course and of academic debates. The Socratic method will be employed to guide discussions when necessary.

Writing will be a mix of product and process approaches (Badger and White, 1993: 158). Peer editing will be based on pre-designed criteria (see Appendix 4, Parts 5 and 6), simulating a university environment and enabling students to discover and understand - on their own terms - the purposes of sentences in paragraphs and of paragraphs in a text. Product-based learning will occasionally be adopted through in-class analysis of authentic or student-produced texts.

\subsection{Materials}

Textbooks will be adapted and combined with authentic materials; through striving to understand ideas in a text, students actively seek ways of understanding its language (Block, 1991). Material types and example sources are presented in Table 5 below.

Table 5 Materials: types and example sources

\begin{tabular}{|c|c|c|c|}
\hline Type & Rati & Objectives & Ex \\
\hline Textbooks & $\begin{array}{l}\text { - can be adapted; provide } \\
\text { structured language/grammar } \\
\text { points. }\end{array}$ & O1, O2, O6 & $\begin{array}{l}\text { - Hewings (2012); } \\
\text { - Zemach and Rumisek (2005). }\end{array}$ \\
\hline Stu & - can be peer edited; topical. & O1, O7, O8 & - from students. \\
\hline $\begin{array}{l}\text { Grading } \\
\text { Criteria }\end{array}$ & - students learn to self-correct. & $\mathrm{O} 3$ & - see Appendix 4, Parts 5 and 6 \\
\hline $\begin{array}{l}\text { Journal } \\
\text { Articles }\end{array}$ & $\begin{array}{l}\text { - authentic texts; can match } \\
\text { students' topics. }\end{array}$ & O4, O5 & - Braakmann (2016). \\
\hline $\begin{array}{l}\text { Online } \\
\text { Videos }\end{array}$ & $\begin{array}{l}\text { - fosters research through } \\
\text { multimedia resources. }\end{array}$ & $\mathrm{O} 4$ & $\begin{array}{l}\text { - London School of Economics } \\
\text { and Political Science (2017) }\end{array}$ \\
\hline
\end{tabular}




\subsection{Constraints and limitations}

Time and space constraints do not allow me to actively monitor students during the research process. I will alleviate this issue through an in-class session on identification and selection of appropriate source materials; while this solution limits the extent to which I can identify potential problems, it simulates a university environment and adds authenticity to the writing process.

The values implicitly promoted by this course stand in contrast to those of some critical EAP (CEAP) scholars who believe that by strictly complying with established academic practices, students 'surrender their own language and modes of thought to the requirements of the target community' (Johns, 1990: 33). Benesch's (2001) elaborate study argues that through imposing stern academic expectations based largely on tradition, most EAP practitioners sustain the power dynamics of reinforcing dominant thought frameworks on students. However, Benesch also believes that students should be allowed to shape their own academic goals, thus creating a potential internal contradiction between a desire for pushing teaching innovation through CEAP and possibly conservative learner demands and expectations for a traditional approach.

In the process of designing this course, I was faced with this exact paradox and employed a pragmatic solution typical for practitioners of traditional EAP. This decision was underpinned by three practical considerations, rather than assumptions about the philosophy of knowledge production. First, my students explicitly stated to me that they primary aim to maximize improvement in their future marks at university - to achieve this, I was (somewhat ironically) incentivised to respond to student demands by maintaining considerable top-down control in terms of the writing standards I imposed.

Second, prior to this course my students had produced neither an argumentative essay, nor an extended piece of writing beyond 1,000 words in English; meanwhile my contact time with the students was limited to only ten three-hour sessions. Although my group was relatively advanced compared to general English learners, the students still faced considerable difficulties to engage in depth with academic debates on subject-specific topics. In this context, potential concerns about the effects of institutional power dynamics remained beyond my immediate priorities. Finally, the cultural background and previous experiences of my students revealed a strong inclination to favour, rather than question hierarchies (Zhu et al., 2016). Ensuring that students would produce substantial arguments for the summative writing assignment on this course was a key aim that had already produced one major conceptual clash with my students' cultural assumptions - adding another one by pursuing a CEAP approach would have likely resulted in setting unachievable goals and objectives, given the short timeframe of my EAP course.

\section{ASSESSMENT}

EAP courses in the UK contain two forms of assessment: formative, 'for learning;' and summative, 'for certification' (Seviour, 2015: 84). The former is aimed at providing feedback for further improvement, while the latter takes place at the end of courses and aims to assess student performance. I will monitor progress and provide guidance through three formative assessments by offering feedback on: a) one argumentative paragraph (Day 3/4), coded F1; b) one introductory paragraph (Day 6/7), coded F2; c) one group discussion (Day 7/8), coded F3, all of which will be on topics selected freely by each student, subject to my approval. The purpose of each formative assessment is listed in Table 6. 
Table 6 Purpose of each formative assessment

\begin{tabular}{|c|}
\hline $\begin{array}{l}\text { F1 will: } \\
\text { - familiarize students with academic marking procedures; } \\
\text { - } \text { check whether students are developing arguments; } \\
\text { - present me with feedback on the efficiency of the first third of the course; } \\
\text { - allow me to make timely adjustments to the course, if necessary. }\end{array}$ \\
\hline $\begin{array}{l}\text { F2 will: } \\
\text { - } \\
\text { - } \text { evaluate a draft of the students' thesis statements; } \\
\text { serve as guidance for the summative assessment. }\end{array}$ \\
\hline $\begin{array}{l}\text { F3 will: } \\
\text { - } \text { help students to refine their arguments. }\end{array}$ \\
\hline
\end{tabular}

This process will build up to a fourth, summative assessment (coded S) at the end of the course. This will be a 1,500-word argumentative essay; through evaluating it, I will determine the extent: a) to which students are ready to produce university-level work with some guidance; b) of student progress towards course objectives listed in section 3.1. Students may change or adjust their final writing topic at any point prior to week 4, conditional on my approval; however, it is desirable for all three formative assessments to cover topics/themes similar to that of their research area and their summative assignment.

\subsection{Task choice: rationale}

A project contains more than one task and spreads over a longer time frame than one class (Bülent and Stoller, 2005). A sequence of formative and summative assessments on one or similar topics thus constitutes a project. Project-based learning (PBL) increases autonomy, enhances motivation and engages the student in the learning process (Egbert, 2003; Dörnyei and Ushioda, 2011). PBL has been successfully implemented in mainland China (Grant, 2017) and it forms a core part of new services offered by educational start-ups in Beijing (e.g. ViaX); hence, I chose to employ it as a course-guiding principle.

Assessment (F1, F2, F3, S) is sequenced as shown in Appendix 6. Paragraphing comes first as: a) students have more experience writing paragraphs, rather than essays; b) it encourages argument building. Providing feedback on an essay introduction midway through the course allows sufficient time for making and/or adjusting topic choice and for refining ideas. Student-led critical discussions in F3 are based on individual research and on draft writings - they take place on Day 7 and provide an opportunity to test ideas in front of fellow colleagues and to also receive tutor feedback on the following day. Summative assessment requirements are designed to simulate a short UK university essay assignment, aiming to create positive washback (Harris and McCann, 1994). The course mainly aims to improve writing skills for university essays; hence, all assessment apart from the discussion is on take-home assignments. Student work will be submitted via e-mail and feedback will follow within seven days of submission. 


\subsection{Criteria: rationale}

Based on Hyland's (1990: 69) three stage analysis of academic writing (thesis, argument, conclusion), this course focuses on the development of argument-based writing and on improving the students' ability to formulate a concise, critical thesis statement which maps out the essay. All criteria (Appendix 4, Parts 1-4) are designed with reference to student weaknesses (Section 2) and course objectives (Section 3). Appendix 4, Part 1 is an open-ended version of the DT criteria to allow for flexible feedback with specific examples. Appendix 4, Part 2 evaluates the elements of an introduction. Appendix 4, Part 3 focuses on critical thinking. These three sets of criteria are designed to measure student progress, to create a positive spin off on students and to allow for timely adjustments to the course, if necessary. Appendix 4, Part 4 is identical to the DT criteria - grading students against the same set of requirements before and after the course provides a clear and quantifiable measure of their progress. All marking contains a subjective element to mirror university essay feedback and grading.

\subsection{Course evaluation}

The course will be evaluated both by me and by the students. I will collate data to produce: a) comparative analysis DT and summative assessment evaluation against the adapted version of the MASUS criteria (Appendix 4, Part 4); b) personal observations. Students will provide: c) group feedback; d) individual feedback. Combining the evaluations of tutors and students is crucial because as Nunan (1993: 139) rightly notes, there might be 'disparities between what teachers believe happens in class and what actually happens'.

The final hour of the course (hour two in session 10) will be a reflective discussion with the students about their experience. In a focus group setting, students can influence each other's responses and thus, the data collected through this discussion will be supplemented by a course feedback questionnaire (Klimova, 2015: 637), handed out to students after the final class and collected electronically by the end of the day. This will aim to identify whether: a) student input from the discussion can be confirmed; b) students make any new suggestions.

\subsection{Constraints}

Time constraints do not allow for one-on-one tutorials - this will, to an extent, be mitigated through active monitoring and in-class feedback, but still remains as a missing feature of the course. Theoretically, take-home assignments could undermine assessment validity as students may reach out for external help or attempt to plagiarize. However, the former is unlikely as students: a) are sufficiently motivated to receive additional feedback; b) have not had access to EAP guidance at their Chinese universities. I will identify plagiarism through: checking student work through my academic account on Turnitin; b) comparing writing styles against samples from DT. These limitations do not impede me from achieving my course aims and objectives.

\section{CONCLUSION}

This course differs fundamentally from general English courses. It incorporates a psycholinguistic introduction to the idea of a discourse community and various critical elements (e.g. self-reflection; peer editing; student-led discussions). In line with such practices, 
authentic materials are used in class and students are required to locate, evaluate and incorporate their own secondary research into formative and summative assessment writing.

While providing guidance as a tutor, I treat students as independent, young academics and provide them with high levels of freedom to choose their research topic. Regardless of the level of work they produce for the summative project, the experience will allow stronger students to excel and weaker ones will learn through assuming greater responsibility for their studies.

\subsection{Course limitations}

The course is limited by design as it does not provide training in key areas of EAP, such as writing for exams, assessed presentations and grammar - students are expected to receive such training on a subsequent pre-sessional course. Time and space constraints do not allow me to monitor students during the research process and to hold one-on-one tutorials; therefore, a substantial amount of self-discovery is required.

Creativity in essay presentation is omitted from the curriculum; it is neither encouraged, nor discouraged but rather ignored in order to avoid detraction from the course's main goals. The curriculum assumes strong student motivation and ample time for preparation at home. Lack or misjudgement of either may result in partial achievement of course objectives (3.1); however, it is unlikely to devalue the strengths of the course.

\subsection{Course strengths}

The course has a practical focus and it purposefully emphasises main priorities which will have a lasting impact on the academic careers of students, rather than simply resolving minor, purely linguistic (e.g. grammar inaccuracy) issues. The course's target outcome (producing a short argumentative essay to a UK university standard) closely mirrors the target situation, creating a learning experience.

Priorities (2.4), goals and objectives (3.1) are derived from NA. Tailoring the course to learner needs has resulted into addressing writing features which students already struggle with and thus, they will inevitably improve.

Finally, incorporating standard university practices (written feedback; formative / summative assessment) teaches a practical skillset to bridge the cultural gap between university systems in the UK and China. Navigating through formative assignment feedback trains students to simultaneously attend to pivotal parts of the writing process and to the assessment criteria which will be used to evaluate the final product. Asking students to identify their own research topics while providing individual guidance in the process means the course can tailor to different levels of critical and language abilities. This makes the course targeted to the needs of all learners identified in Section 2.

\subsection{Broader implications}

This article documents the academic writing course design process for advanced Chinese graduates aiming to pursue postgraduate study in business-related fields in the UK. It identifies areas of course design which are often approached differently by EAP practitioners who might choose to place a greater focus on institutional expectations as opposed to those who prioritise student needs. This tension fundamentally stems from a clash between top-down expectations imposed through established practices within academic communities 
and bottom-up needs specific to different student groups. The article presents a middle-ground approach to resolving these tensions through making a case for balanced course design by combining key EAP principles with needs analysis. The course design offers practical solutions to problems faced frequently by EAP practitioners, offering middle-ground solutions which simultaneously incorporate institutional and student expectations while minimising limitations.

\section{REFERENCES}

Alexander, O., Argent, S., and Spencer, J. 2008. EAP Essentials: A Teacher's Guide to Principles and Practice. Reading: Garnet Publishing.

Ardi, P. 2017. Promoting learner autonomy through schoology m-learning platform in an EAP class at an Indonesian University. Teaching English with Technology, 17 (2), 55-76.

Badger, R. and White, G. 2000. A Process Genre Approach to Teaching Writing. ELT Journal, 54, 153-160.

Benesch, S., 2001. Critical English for Academic Purposes: Theory, Politics, and Practice. New York: Routledge.

Bensal, E., Miraflores, E. and Tan, N., 2013. Plagiarism: Shall we turn to Turnitin? Computer-Assisted Language Learning Electronic Journal, 14 (2), 2-22.

Block, D. 1991. Some Thoughts on DIY Materials Design. ELT Journal. 45(3), 211-217.

Bonanno, H. and Jones, J. 2007. The MASUS procedure: Measuring the Academic Skills of University Students, A Diagnostic Assessment. University of Sydney: Learning Centre Publications.

Braakmann, N. 2016. The link between crime risk and house prices - Evidence from UK street-level data. Urban Studies, 54(8), 1990-2007.

Brown, J. D. 1995. The Elements of Language Curriculum: A Systematic Approach to Program Development. Boston, Massachusetts: Heinle \& Heinle.

Bülent, A. and Stoller, F. 2005. Maximizing the benefits of project work in foreign language classrooms. English Teaching Forum, 43(4), 10-21.

Coxhead, A. 2000. A New Academic Word List, TESOL Quarterly, 34(2), 213-238.

Denzin, NK. 1978. Sociological Methods. New York: McGraw-Hill.

Dörnyei, Z. and Ushioda, E. 2011. Teaching and researching motivation (2nd Ed.). Harlow: Pearson Education.

Egbert, J. 2003. A study of flow theory in the foreign language classroom. The Modern Language Journal. 87(4), 499-518.

Fleming, N. and Mills, C. 1992. Not Another Inventory, Rather a Catalyst for Reflection. To Improve the Academy, 11, 137-155.

Gardner, P. and Winslow, J. 1983. Present and Proposed Methods of Determining the Needs of Students in Public Sector Identifying Language Needs. In: Richterich, R. (Ed.). Case Studies in Identifying Language Needs. Oxford: Pergamon Press, 69-78.

Grant, S. 2017. Implementing project-based language teaching in an Asian context: a university EAP writing course case study from Macau. Asian-Pacific Journal of Second and Foreign Language Education, 2(4), 1-13.

Graves, K. 2000. Designing Language Courses: A Guide for Teachers. Boston: Heinle \& Heinle.

Hamp-Lyons, L. 2005. English for Academic Purposes. Handbook of Research in Second Language Teaching and Learning. UK: Routledge, 89-105. 
James, M., Miller, G. and Wyckoff, T., 2019. Comprehending the Cultural Causes of English Writing Plagiarism in Chinese Students at a Western-Style University. Journal of Business Ethics, 154 (3), 631-642.

Johns, A. 1990. L1 Composition Theories: Implications for Developing Theories of L2 Composition. In: B. Kroll (Ed.), Second Language Writing: Research Insights for the Classroom. New York: Cambridge University Press, 24-36.

Klimova, B. 2015. Designing an EAP Course. Social and Behavioural Sciences, 191, 634-638.

Lethaby, C. and Harries, P. 2015. Learning Styles and Teacher Training: Are We Perpetuating Neuromyths?. ELT Journal, 70, 16-25.

Lockett, A. 1999. From the general to the specific: What the EAP tutor should know about academic discourse? in Bool, H. and Luford, P. Academic standards and expectations: The role of EAP, Nottingham: Nottingham University Press, 49-58.

LSE (London School of Economics and Political Science). 2017. Lecture 3. Cultivating the Virtues of Globalization. Available at: https://www.youtube.com/watch?v=oZcTiMF wZ6o (Accessed: 10 Nov, 2019)

Lynch T. 1988. Peer evaluation in practice. In: A. Brookes and P. Grundy (Eds.), Autonomy and Individualisation in Language Learning. ELT Documents 131. London: MEP / British Council, 119-25.

Lynch T. 2013. Not just talking: Conversation and perceived progress in international students' informal language learning. International Student Experience Journal, 1(2): $1-8$.

Mauranen, A. 2006. A Rich Domain of ELF: The ELFA Corpus of Academic Discourse. Nordic Journal of English Studies, 5(2), 145-159.

Maas, C. 2017. Receptivity to learner-driven feedback in EAP. ELT Journal, 71(2), 127-140.

Mattison, J. 2007. Chinese essay writing: a special challenge for universities in the West: a discussion of Chinese students' essay writing traditions and Western praxis. In: Eskilsson, O. and Redfors, A. (Eds.). Ämnesdidaktik ur ett nationellt och internationellt perspektiv: rapport från Rikskonferensen i ämnesdidaktik. Sweden: Kristianstad University, 153-160.

McEnery, T., Xiao, R. and Tono, Y. 2006. Corpus-Based Language Studies: An Advanced Resource Book. London: Routledge.

Nesi, H. 2008. Corpora \& EAP. In: LSP: Interfacing Language with other Realms: Proceedings of the 6th Languages for Specific Purposes International Seminar. Universiti Teknologi Malaysia.

Harmer, J. 2001. The Practice of English Language Teaching. Essex, UK: Longman.

Harwood, N. 2005. What do we want EAP teaching materials for? Journal of English for Academic Purposes, 4(2): 149-161.

Hewings, M. 2012. Cambridge Academic English C1 Upper Intermediate Student's Book: An Integrated Skills Course for EAP. Italy: Cambridge University Press.

Hyland, K. 1990. A Genre Description of the Argumentative Essay. RELC Journal, 21, 66-78.

Kashef, S. 2014. Toward a Learning-centred EAP Instruction: An Attempt to Change Students' Reading Attitude. Theory and Practice in Language Studies, 4(1), 39-45.

Nunan, D. 1988. Syllabus Design. Oxford: Oxford University Press.

Nunan, D. 1993. Task-based syllabus design: selecting, grading and sequencing tasks. In: Crookes, G., Gass, S. (Eds.). Tasks in a Pedagogical Context: Integrating Theory and Practice. Cleveland, UK: Multilingual Matters. 
Unlu, Z. and Wharton, S. 2015. Exploring classroom feedback interactions around EAP writing: A data based mode. Journal of English for Academic Purposes, 17, 24-36.

Schmitt, D. and Schmitt, N. 2005. Focus on Vocabulary: Mastering the Academic Word 1st Edition. Pearson Education ESL.

Seviour, M. 2015. Assessing Academic Writing on a Pre-sessional EAP course: Designing Assessment which Supports Learning. Journal of English for Academic Purposes, 18, 84-89.

Spack, R. 1988. Initiating ESL Students into the Academic Discourse Community: How Far Should We Go? TESOL Quarterly, 22(1), 29-52.

Stoller, F. 1999. Time for Change: A Hybrid Curriculum for EAP Programs. TESOL Journal, 8, 9-13.

Swales, J. 1990. Genre Analysis: English in Academic and Research Settings. Boston: Cambridge University Press.

Swales, J. 1995. The Role of the Textbook in EAP Writing Research. English for Specific Purposes, 14, 3-18.

Tardy, C. 2004 The role of English in scientific communication: lingua franca or Tyrannosaurus rex? Journal of English for Academic Purposes, 3(3), 247-269.

Thornbury, S. (2013). S is for Student-centered. Online video clip. Youtube, 22 May. Web. Available at: https://www.youtube.com/watch?v=rl_n2jm0fJY (Accessed: 20 Nov 2019)

West, R. 1994. Needs Analysis in Language Learning. Language Teaching. 27(1), 1-19.

Xu, Y., 2015. Indirectness in Chinese Students' Academic Essays. English Teaching in China, 6, 36-41.

Zemach, D. and Rumisek, L. 2005. Academic Writing from Paragraph to Essay. Oxford: Macmillan.

Zhu, X., Wang, L., Yang, S., Gu, R., Wu, H and Luo, Y. 2016. The Motivational Hierarchy between the Personal Self and Close Others in the Chinese Brain: an ERP Study. Frontiers in Psychology. 27(7), 1-7.

\section{APPENDICES 1-6}

Supplementary data is available online via the following URL: https://drive.google.com/open?id=1MuphS8NbtnLlp3UORhIAlXIpUKXNKBQH 